\title{
Escola, gênero e gestão em ação: um estudo de caso em Portugal
}

\author{
School, gender and management in action: a case study in Portugal \\ Escuela, género y géstión en acción: un estudio de caso en Portugal
}

\section{MARIA CUSTÓDIA JORGE ROCHA TÂNIA SUELY ANTONELLI MARCELINO BRABO}

\begin{abstract}
Resumo: Tem-se assistido a um crescente pluralismo no que diz respeito à investigação sobre os contextos organizacionais e os da gestão na sua correlação com os estudos sobre as relações de gênero. Esses estudos são influenciados por conceções, pressupostos e princípios que tendem a reproduzir e a fortalecer a divisão institucional moderna e racionalizadora entre gestão educativa e gênero feminino. Partindo de um estudo de caso através de uma análise crítica dos discursos organizacionais, constatamos como homens e mulheres percecionam e atualizam suas práticas cotidianas de gestão escolar que, apesar de condicionadas pelo peso das estruturas de representação diferenciadoras das suas funções de gestão, são produtores de novos sentidos, de novas lógicas de ação, que a literatura organizacional deverá contemplar, (re)questionandoos à luz das premissas da "gestão da diversidade" e da "gestão estratégica".
\end{abstract}

Palavras-chave: Escola. Gênero. Gestão Educacional. Portugal.

Abstract: There has been a growing pluralism with regard to research on the organizational context and management in its correlation with the studies on the social relations of gender. These studies suffer the influence of conceptions, assumptions and principles that tend to reproduce and strengthen the modern and rationalizing institutional division between educational management and female gender. Starting from a case study and through a critical analysis of organizational discourse, we see how men and women perceive and actualize their daily practices of school management. Although they are conditioned by the duty of the distinctive representation structures of their management function, they are producers of new meanings and new logics of action that should be included on the organizational literature, (re) questioning them in the light of the premises of "diversity management" and "strategic management".

Keywords: School. Gender. Educational Management. Portugal.

Resumen: Ha habido un pluralismo cada vez mayor con respecto a la investigación sobre el contexto y la gestión de la organización en su correlación con los estudios sobre las relaciones sociales de género. Estos estudios se ven influidas por concepciones, supuestos y principios que tienden a reproducir y reforzar la división institucional moderno y racionalización entre la gestión educativa y hembras. A partir de un estudio de caso ya través de un análisis crítico del discurso organizacional, vemos cómo los hombres y las mujeres perciben y actualizan sus prácticas diarias de gestión escolar que, aunque 
condicionada por el peso de las estructuras de representación diferencial de sus funciones de gestión, son productores nuevos significados, nuevas lógicas de acción que deberían incluir la literatura organizacional, (re) el interrogatorio a la luz de las premisas de "gestión de la diversidad" y "gestión estratégica".

Palabras clave: Escuela. Género. Gestión de la Educación. Portugal.

\section{INTRODUÇÃO}

Fruto de "uma divisão institucional entre razão e emoção, divisão essa que acompanhou de perto as linhas do gênero" (GIDDENS, 2001, p. 140), e que caracterizou o desenvolvimento das sociedades modernas, a investigação sobre o mundo laboral e sobre as funções de gestão nas organizações recaiu, até meados do século XX, exclusivamente sobre os homens trabalhadores/gestores.

Foi sobretudo com os estudos realizados pelas mulheres feministas que se acrescentaram à agenda da investigação, ainda que marginalmente, por vezes, as experiências das mulheres profissionais e em postos de gestão (MARSHAL, 1984; HEARN et al., 1992). Esses factos levam a falar na existência de uma "natureza androcêntrica da teoria e investigação" (SHAKESHAFT, 1989, p. 151-162) no seio dos estudos que se debruçam sobre as organizações em geral e sobre as organizações educativas: "um estudo de dez anos de investigação sobre a revista Educational Administration Quarterly identificou conceptualizações e métodos androcêntricos na maioria dos artigos" (Ibidem).

A partir de um quadro teórico em que se manifesta a natureza androcêntrica da investigação e a masculinização da gestão escolar, mas sem deixar de atender a outras perspetivas de análise, desenvolvemos um estudo de caso único, de tipo exploratório, de cariz qualitativo, com um extenso suporte de teorização (ROCHA, 2007a) ${ }^{1}$. Consideramos, à altura, que este estudo de caso poderia constituir a base de posteriores trabalhos académicos. Veja-se que muitas investigações começam sob a forma de um estudo de caso único cujos resultados vão servir para se proceder à elaboração de casos múltiplos (BOGDAN; BIKLEN, 1994; YIN, 2001).

Ao longo de nosso processo de investigação, temos vindo a defender uma conceção de organização escolar - e de gestão - enquanto loci de ação onde se entrecruzam elementos ambíguos, simbólicos, culturais, subjetividades, racionalidades e relações de poder várias. Trata-se de elementos e de relações de grande complexidade e que devem ser tidos na sua interseção em caso de

\footnotetext{
Esse estudo foi efetuado em Portugal aquando da vigência do Decreto-lei n ${ }^{\circ}$. 115-A/98, de 4 de Maio, com as posteriores alterações da Lei no. 24/99, de 22 de Abril, e faz parte integrante de trabalhos de Doutoramento na Área de Organização e Administração Escolar.
} 
investigação empírica. Tudo isso tem levado a ponderar sobre a metodologia de investigação a se utilizar em estudos sobre gênero e a insistir numa necessária utilização de métodos e técnicas de investigação - de recolha e análise de dados dando relevância à análise crítica dos discursos organizacionais (ROCHA, 2007b).

Neste artigo destacamos as ideias que ressaem do estudo de caso atrás referenciado (ROCHA, 2007a), a partir, precisamente, da análise crítica dos discursos organizacionais que o enformam. Trata-se de uma técnica metodológica em que se consideram tópicos de análise discursiva e se procede à análise crítica dos dados, leia-se, discursos tendo como finalidade a desconstrução de alguns pressupostos existentes sobre gênero, gestão, poder, discurso, entre outros (ROCHA, 2008b). Um constante confronto entre os discursos instituídos, por exemplo pelo Estado, e os discursos instituintes produzidos pelas mulheres e pelos homens no contexto de ação organizacional permite mostrar como os discursos devem ser tidos na sua dualidade - o discurso e o sentido, - tal como o poder; aliás, não são só elementos de reprodução que constrangem, são também relações de desconstrução que capacitam (ROCHA, 2007a,b).

\section{A CONSTRUÇÃO GENERIZADA² DA GESTÃO}

As primeiras teorias sobre gestão foram desenvolvidas por homens, dentre os quais se destacam Taylor, Fayol, Barnard, Simon e Weber (ENOMOTO, 2000). Essas teorias muito contribuíram para a "racionalização da produção do género" (ALVESSON; BILLING, 1992, p.78), assim reforçando a "interiorização de critérios distintivos entre os géneros" (GIDDENS, 1994, 2001) e, assim, consolidando a ideia de que "pensar em gestão é pensar em masculino" (Schein, apud O’LEARY; RYAN, 1994, p. 67).

$\mathrm{Na}$ organização racional do trabalho defendida por Frederick Taylor, as mulheres ocuparam postos de trabalho menos qualificados e pior remunerados. Procurava-se, aqui, adequar as características psicofísicas dos indivíduos aos postos de trabalho, obviamente de acordo com uma lógica de divisão "natural" do trabalho entre homens e mulheres (FREIRE, 1993, p. 66). Máquinas não eram para mulheres, a não ser as de escrever. E, no que se refere às grandes funções associadas à gestão por parte dos teóricos das organizações modernas, estas eram

2 Os neologismos generizada(s), generizado(s) são assumidos neste trabalho enquanto tradução do termo anglo-saxónico genderized. Prevalece na literatura portuguesa a utilização do neologismo "generificado" ou "genderizado" quando autoras e autores se querem referir a um processo ou a uma prática social que é constituída e constituinte dos géneros ou para se referir a algo que está relacionado ao gênero. A opção pela utilização do neologismo generizada(s), generizado(s), neste e noutros trabalhos, deve-se ao facto de este neologismo constituir, em si, um particípio verbal simultaneamente ativo e causativo que implica fundamentalmente a ideia de que algo/alguém provoca e/ou é causa de ações e contextos que resultam e/ou se manifestam marcados por conceções (muitas vezes estereotipadas) no que às relações de gênero diz respeito. 
implicitamente consideradas como só sendo possível ser levadas a cabo pelos homens, como sendo, em suma, "as funções do executivo" (BARNARD, 1971).

No que diz respeito aos critérios da racionalidade burocrática, os estudos weberianos, se, por um lado, revelaram-se profícuos no que se refere, por exemplo, a "desocultação" que Max Weber faz da "autoridade patriarcal", com estes mesmos estudos pouco se fez no que concerne à transposição das implicações "destas análises estruturais do género para o nível organizacional" (HEARN et al., 1992, p. 9).

Assim, e pese, embora, o interesse manifestado por Max Weber pela reflexão sobre o "patriarcado", esse autor é acusado de se ter silenciado acerca do papel das relações de género no desenvolvimento do capitalismo, sendo que o seu conceito de racionalidade reflete "uma noção masculina tradicional de racionalidade" (MILLS, 1993, p. 134). O conceito de racionalidade burocrática assenta-se, então, na ênfase colocada na lógica, no cálculo e no afastamento de qualquer tipo de emotividade. As manifestações ditas "irracionais", vulgarmente associadas ao gênero feminino, tais como impulsos, desejos e sentimentos, são depreciadas pelos critérios da racionalidade burocrática. É, de fato, Max Weber (1979 p. 251) quem adverte: "a burocracia é desumanizada, na medida em que consegue eliminar dos negócios oficiais o amor, o ódio, e todos os elementos pessoais, irracionais e emocionais que fogem ao cálculo" (Ibidem).

Dessa forma, os pressupostos da racionalidade burocrática e da teoria da burocracia, enquanto "tipo ideal" têm permitido concetualmente colocar a burocracia numa oposição direta com o feminismo, na medida em que se considera a teoria clássica da burocracia desenvolvida por Max Weber e as apropriações de seus seguidores extremamente conectadas à racionalização das relações interpessoais e à legitimação da dominação masculina: "a burocracia enquanto 'organização científica da desigualdade' serve como um filtro para outras formas de dominação - as de classe, raça, assim como as de (sexo) género - configurando uma arena que ao mesmo tempo que as racionaliza, as mantém" (FERGUSON, 1984, p. 4-27).

Foi assim, pode dizer-se, que "a noção de 'objetividade' e 'racionalidade' masculinas se transformaram nas palavras de ordem das burocracias", sendo que "a associação do feminino à subjetividade e à irracionalidade excluiu as mulheres da possibilidade de dirigir e gerir" (MORGADE, 1998, p. 76-77). Desta feita, as conceções sobre gestão escolar estão intimamente associadas à “dureza” do núcleo "masculino" desse contexto, em que se tende a associar gestão ou administração "a um determinado tipo de masculinidade - a do heterossexual, branco, racional e tecnicamente capaz" e "dotado de poder".

Essas críticas à forma como as organizações têm sido analisadas e às 
implicações dessa análise para a compreensão das relações de género no âmbito das organizações estendem-se a muitas escolas de pensamento e não só à organização científica do trabalho e à teoria da burocracia.

No âmbito da teoria das relações humanas, conceitos como os de organização informal, liderança formal e informal, homo socialis, por oposição ao homo aconomicus, clima, moral, comunicações na empresa, resistência à mudança, superioridade dos processos participativos sobre os autoritários e tecnocráticos foram considerados na base de um entendimento de género que mostra o carácter tecnocrático e androcêntrico das ações administrativas. Esses conceitos, aliás, foram propiciados pela continuidade e afirmação das ideologias de modernização da administração e das organizações (VARGHESE, 1990). Por isso, diz-se que a escola das relações humanas, com a experiência que desenvolveu em Hawthorne, por exemplo, "falhou em considerar a composição em termos de género dos grupos de trabalho estudados" e apresentou, assim, "uma perspetiva gender-blind das organizações” (HALFORD; SAVAGE; WITZ, 1997, p. 5).

A teoria funcionalista da estratificação social de Talcott Parsons, por volta dos anos 40 e 50, é também apontada e sujeita a críticas, havendo mesmo quem considere que, de alguma forma,

Parsons, Bales e os seus colegas exacerbaram o problema do género na teoria organizacional baseando as suas análises em concepções implícitas de masculinidade ou até em pressupostos explícitos acerca da masculinidade e feminilidade das performances organizacionais e de outros sistemas sociais. (HEARN et al., 1992, p. 9).

Análises teóricas bastante prescritivas, tecnocráticas e androcêntricas sobre a problemática das relações de género estão patentes em muitos estudos de teor académico. A título de exemplo, veja-se a análise efetuada, nos finais dos anos sessenta, por Amitai Etzioni (1969) sobre o ensino, o trabalho social, a enfermagem e o trabalho bibliotecário, e o enquadramento que o autor faz dessas profissões enquanto semiprofissões, por serem altamente feminizadas. Veja-se, também, a análise que Richard Simpson e Ida Simpson (1969) fazem da presença das mulheres nas organizações escolares, defendendo explicitamente que essa presença é o critério responsável pelo reforço do controlo burocrático e pela ênfase colocada na autoridade hierárquica e nas regras e, ainda, que essa presença, em si, é o critério responsável pela pouca autonomia dos trabalhadores das organizações escolares.

As teorias sistémicas e contingenciais, por seu turno, "apresentam como principal fraqueza a aceitação e o não questionamento da noção weberiana da burocracia” (HALFORD; SAVAGE; WITZ, 1997, p. 9), que, "apoiada em hierarquias, procedimentos e tarefas impessoais conducentes à mais racional e 
eficiente forma de organização" (Ibidem), faz "desaparecer as tradicionais formas de poder e discriminação baseadas, por exemplo, no sexo ou nas características de classe" (Ibidem).

Com as perspetivas organizacionais anteriormente sinalizadas, muito se reforçou a institucionalização das desigualdades de género na gestão das organizações educativas. Contudo, é o estudo dessas mesmas perspetivas (e dos critérios que as enformam) que possibilita mostrar como

Os problemas da exclusão [das mulheres] dos cânones dos estudos organizacionais são particularmente acutilantes para investigações que focalizem a problemática do sexo e do género [...] permitindo a presunção de que a investigação organizacional é neutra do ponto de vista das relações de género. (MARTIN, 1994, p. 418)

O estudo dessas mesmas perspetivas organizacionais leva mesmo a concluir que

As tentativas que ao longo do século se fizeram para atacar o coração das estruturas hierárquicas (desde o discurso organizacional das 'relações humanas' até às pressões contingenciais) estiveram impregnadas de uma forma patriarcal de significado no que respeita as relações de género, ainda que alberguem sementes de transformação. (MORGADE, 1998, p. 77).

O carácter androcêntrico da investigação sobre as relações de gênero tem sido apontado como estando até subjacente aos estudos que enformam a teoria crítica. Como no-lo reporta Nancy Fraser (1990, p. 51), "Habermas não diz virtualmente nada acerca do género na Teoria da Acção Comunicativa". Acrescenta a autora: "Ora bem, de acordo com a minha conceção da teoria crítica, trata-se de uma séria deficiência" (Ibidem). Essa deficiência é explicitada por Iris Young (1990, p.106-107) que, apesar de reconhecer que "a teoria da ação comunicativa de Habermas tem muito mais a oferecer a uma ética feminista que a teoria ética e política modernas", reconhece também, entre outros aspetos, que Jürgen Habermas com a sua "fé na possibilidade do consenso como uma condição para que o diálogo se inicie [...] conserva o compromisso com a imparcialidade e reproduz na sua teoria da comunicação uma oposição entre razão e desejo"(Ibidem).

A partir dos anos 70 do século XX, houve uma explosão da produção académica feminista em várias disciplinas e também na teoria organizacional. Contudo, a discussão feminista tem adquirido um carácter restritivo, também nesse âmbito, já que, a não ser excecionalmente, a problematização das relações de gênero "tem sido inscrita na teoria organizacional por vias incompletas e inadequadas" e foi feita, quantas vezes, "fora dos limites da teoria organizacional" (CALÁS; SMIRCICH, 1992, p. 227-228).

Os estudos de carácter acadêmico, de teor feminista ou não, e inscrevendo- 
se no âmbito de análise da problemática género e gestão educativa, conheceram, a partir dos anos 70 do século XX, uma grande proliferação. Trata-se de estudos que, pese, embora, sua pluralidade, primam por assinalar, com base em dados estatísticos que, no âmbito da gestão escolar, as mulheres foram "demasiado poucas durante demasiado tempo" (SHAKESHAFT, 1989, p. 20), por exemplo no caso dos Estados Unidos e em diversos países do mundo, aí incluídos dez países europeus, o que permite afirmar:

A história da administração escolar documenta uma consistente dominação masculina a todos os níveis, exceto durante um curto espaço de tempo durante o qual as mulheres alcançaram uma débil maioria na direção de algumas escolas urbanas. (SHAKESHAFT, 1999, p.101).

Em Portugal, "nos últimos 15-20 anos têm surgido estudos de carácter científico sobre as problemáticas da igualdade de género, mas os seus conteúdos dificilmente permeiam a prática das administrações a ponto de influenciarem os seus procedimentos correntes" (SILVA, 1999, p. 25). Para a clarificação dessa ideia, teremos de reiterar, tal como já fizemos em outros estudos, que, em Portugal, o contexto de produção dos discursos legalmente instituídos, o nível estatal e jurídico de produção normativa, pode ser visto como um contexto que favorece a delineação de um sistema que tende a instituir uma organização coletiva das formas de comportamento e atuação. No âmbito da administração educacional, em Portugal, o Estado, e os atores sociais, propiciaram a consolidação de uma imagem em que os papéis do masculino e do feminino na gestão das organizações educativas estão de acordo com os critérios do pensamento organizacional racionalista, que tende a orientar os domínios do público e do privado (ROCHA, 2007a).

O Estado Novo, no que a isso diz respeito, desempenhou papel crucial "impedindo as professoras de aceder a cargos diretivos nas escolas" (ARAÚJO, 1990, p.89). E,

Durante vários anos a escola veiculou e mesmo contribui para acentuar, por diferentes meios, a discriminação sexual existente na época e na sociedade portuguesa. A mulher foi explicitamente reduzida a uma posição subalterna, foram lhe dificultados acessos e vedados lugares [...] as professoras constituíram, pela educação que tinham recebido, um dócil instrumento conservador apreciado pelo sistema. (CORTESÃO, 1988, p. 152-153).

Em termos de gestão escolar, a imagem que ressai do sistema educativo português, à altura do Estado Novo, era uma imagem de 
Desvalorização da mulher. Os lugares da hierarquia eram normalmente ocupados pelos homens (delegações, direções escolares, conselhos diretivos, inspeção, direções regionais, Ministério da Educação. Os homens estavam mais presentes nos níveis mais elevados de ensino. Os postos auxiliares e de limpeza eram normalmente desempenhados por mulheres, com exceção de alguns lugares ligados à disciplinação e ao controlo dos comportamentos (contínuos, segurança). Os sindicatos do professorado eram normalmente dirigidos por indivíduos do sexo masculino. Mesmo nos cursos esmagadoramente frequentados por raparigas, a maioria dos professores eram homens e professoras catedráticas eram uma raridade. (MAGALHÃES, 1998, p. 150-151).

Em Portugal, a participação e representatividade equitativas na gestão escolar, em termos de gênero, não estão consagradas em nenhum normativo da gestão democrática (nem tão pouco da autonomia e gestão das escolas) e quedamse na genérica pretensão, exposta na Lei de bases do Sistema Educativo (Lei ${ }^{\circ}$ 46/86, de 14 de Outubro, art. ${ }^{\circ}{ }^{\circ}$, al. j) de, em educação, se "assegurar a igualdade de oportunidades entre ambos os sexos, nomeadamente através das práticas de coeducação e da orientação escolar e profissional, e sensibilizar, para o efeito, o conjunto dos intervenientes no processo educativo".

Temos, em Portugal, estudos em que se revela que a designada gestão democrática, após Abril de 1974, não propiciou paridade no que respeita à participação e representatividade de homens e de mulheres em cargos de gestão escolar, o que, entre outros aspetos, obrigou a que se propusesse a "reforma do contexto da gestão das escolas, dando voz aos conselhos diretivos" (SANCHES, 1987) e a mostrar como, neste país,

As mulheres dominam numericamente todos os níveis do sistema educativo sem se verificar uma correspondente representação nos respetivos órgãos de decisão dos vários estabelecimentos e instituições escolares e educacionais. (TRIGOSANTOS, 1997, p.239).

Um levantamento estatístico permitiu confirmar a "masculinização da gestão escolar" ao longo dos tempos em Portugal (ROCHA, 1997) e, especificamente, no período da gestão democrática (ROCHA, 1998). Em outros estudos, e a partir de dados obtidos em 1995, conseguiu-se mesmo traçar um "retrato-tipo" dos "diretores executivos", destacando-se "a elevada taxa de masculinização existente entre os diretores executivos, não só em termos absolutos, mas tendo em conta a distribuição do corpo docente pelos dois géneros" e considerando, mesmo, que a taxa de masculinização da gestão foi reacentuada com a implementação, a nível experimental, do Decreto-lei 172/91 (BARROSO, 2002, p.102).

Estudos efetuados ainda em Portugal, no início do século XXI, a partir de amostras representativas de "presidentes de conselhos executivos" ou "diretores 
executivos" em funções, revelam que:

Quanto ao Presidente do Conselho ou Diretor Executivo, os docentes que exercem a função de topo na gestão das escolas ou agrupamentos mostram um perfil caracterizado por um índice de feminização muito inferior ao do conjunto do corpo docente, havendo [no entanto, no exercício dessa função] quase tantos docentes do género masculino como do género feminino. (AFONSO; VISEU, 2001, p.42).

A lei, em Portugal, sendo omissa no que respeita à consagração da participação e da representatividade dos homens e das mulheres na gestão das escolas, facilita, na nossa perspetiva, as possibilidades, mesmo tendo em conta os "pressupostos de género na gestão", de as mulheres e de os homens poderem, nas suas escolas, escolher quem os pode representar nos cargos de gestão e concorrer de igual modo a esses cargos de gestão. O seguinte ponto de análise desta reflexão dá conta de alguns indícios que nos permitem falar de uma tentativa de superação dos limites da teoria organizacional clássica e, mais concretamente, da gestão das organizações educativas, quando associados com a problemática das relações de gênero.

\section{A DESCONSTRUÇÃO DA GESTÃO GENERIZADA}

No estudo de caso atrás referido (ROCHA, 2007a), a imagem generizada da gestão das escolas é vista a par com outra: a que trata de pôr o gênero, o poder e a gestão em ação, a que é conseguida pela captação dos discursos instituintes dos homens e das mulheres, a que mostra, mesmo que fugazmente, as relações e interseções que se operam no contexto de ação da gestão organizacional escolar. Pois a análise dos discursos organizacionais (e que contempla tanto as formações discursivas instituídas como as manifestações discursivas instituintes) permite uma configuração da organização escolar, e da sua gestão executiva, como contextos institucionais atravessados por múltiplas racionalidades e poderes. No contexto da gestão escolar, formações discursivas políticas, estatais e ideológicas (incluindo as de gênero, as de poder e as de gestão) confrontam-se com outras manifestações discursivas que tanto reproduzem o instituído como produzem o instituinte. Em última instância, a análise desses discursos organizacionais permite-nos salientar a existência de conceções, racionalidades e práticas na educação e na gestão educacional nem sempre em correspondência com os critérios da racionalidade formal patente nas teorias organizacionais tradicionais, nem sempre de acordo com as bases ideológicas instituídas que as sustentam.

Vejamos. Em contextos específicos de gestão escolar, homens e mulheres possuem poder, mais que não seja "um mínimo de poder" e mais que não seja 
exercido por momentos: uma gestora diz: "eu acho muito bem, as pessoas não se devem fixar nos cargos de poder, porque, apesar de tudo, há sempre algum poder". Um homem, que sai com o Presidente, diz: "estive a discutir com o poder" e, virando-se para uma gestora (Vice-presidente), pergunta: "tu também és do poder ou és auxiliar do poder?" Ao que ela responde: "sou polivalente, faço as duas coisas. Depende da situação”.

$\mathrm{Na}$ gestão da escola, homens e mulheres, muitas vezes, reconstroem pressupostos de género ao enunciar o que pensam sobre ser homem (racional) e ser mulher (emotiva), reconstrução essa que está em acordo com os pressupostos tradicionais de gênero e com poderes ideologicamente instituídos. Vejamos os seguintes excertos discursivos enunciados por mulheres professoras:

Não sei como lhe explique! As mulheres são um tanto ou quanto primárias! Não é bem primárias que eu quero dizer, é mais [...] são mais ligadas às emoções. Isto, claro que tem de interferir na forma como elas fazem as coisas e se não interfere é porque às vezes elas imitam os homens, querem ter poder como eles. Mas, no fundo, a base está lá.

E ainda:

Eu, sinceramente penso que a escola é muito melhor gerida quando a escola tem um Conselho Executivo em que para além dos homens também estão mulheres. As mulheres são muito mais sensíveis aos problemas e, por isso, em certos aspetos, conseguem compreender melhor um mundo escolar que é essencialmente um mundo feminino, não é? Embora as coisas estejam a mudar.

Contudo, também homens e mulheres, não raras vezes, põem em questão a institucionalização dos processos culturais e das formas organizacionais generizadas; desmontam os pressupostos tradicionais de género, discutem publicamente as novas versões de velhos estereótipos, advogam a necessidade de mudança, ou afirmam mesmo a existência de uma mudança já operada no que diz respeito às relações que entre si se estabelecem. É uma mulher quem clarifica:

Há muitos anos que sou professora. Na primeira escola em que fui colocada havia uma diretora, uma pessoa excelente, depois tanto tive a oportunidade de ver homens e mulheres na gestão do Conselho Diretivo. Homens, regra geral, como Presidentes, mulheres como Vice-presidentes. Uma regra que, penso, se tem vindo a alterar, conheço muitas mulheres Presidentes de Conselhos Diretivos, agora, Conselhos Executivos. Não penso que a questão do poder dos homens e do poder das mulheres, nas escolas, possa fazer sentido durante muito mais tempo.

Há, pois, no caso em estudo, discursos instituintes atualizados por homens e por mulheres que permitem um questionamento das relações de poder instituído e que contrariam a ideia de que na escola se favorecem os preconceitos 
masculinos da cultura organizacional. Trata-se de num contexto em que as mulheres são encorajadas para a ocupação de cargos de gestão/direção: "no fim do mandato e com a sua aposentação, o Presidente propôs que continuássemos com a equipa, reorganizada. Decidimos que eu seria a Presidente".

Esses discursos instituintes permitem, até, desconstruir a metáfora da dureza do núcleo masculino da gestão: atendamos às palavras do Presidente do Conselho Executivo:

Eu trabalhei tanto com mulheres como com homens. Há mulheres competentes e homens incompetentes e vice-versa. O poder no masculino e o poder no feminino não é argumento: isto é do domínio cultural e paulatinamente vai mudando. Aquilo da 'mão forte' na gestão significa o quê? Que uma pessoa para gerir uma escola tem de andar à estalada?

A diferenciação assimétrica entre os homens e as mulheres em contexto organizacional escolar é diluída em alguns desses discursos, sobretudo naqueles que questionam os pressupostos da especificidade própria das práticas de gestão dos homens em relação às mulheres.

É uma mulher quem coloca a seguinte questão:

Por que é que se pergunta sempre se as mulheres são diferentes na gestão e não se coloca essa questão sobre os homens? Porque a gestão sempre foi uma coisa de homens e as mulheres ao entrar nela seriam como que automaticamente diferentes. É com isto que eu não concordo. Nesta escola, este problema, pelo menos agora não se coloca. Há mulheres que trabalham de igual forma aos homens no Conselho Executivo.

Pergunta uma outra mulher: "a autonomia das escolas de que agora se fala muito não é só para os homens gestores, pois não?” A mesma mulher afirma, sem hesitar: "as mulheres também estão em fase de autonomia e de poder". E, perante a mesma problemática em análise, diz um homem: "a escola precisa de ser gerida, por quem? Por homens? Por Mulheres? Tanto faz, desde que haja disponibilidade e competência para o fazer". Veja-se, ainda a esse propósito, o quão humanizante é o discurso de um outro homem:

Eu gostava que nas escolas, na gestão das escolas, houvesse outras solidariedades, outras compreensões. Mais carinho [...] tanto por parte das mulheres como dos homens [...] acho que não há diferença entre a gestão dos homens e a das mulheres nas escolas [...] até há homens que são mais afetivos e mais atenciosos do que as mulheres [...]. 


\section{OS DITAMES DA ERA DA NOVA GESTÃO: A GESTÃO GENERIZADA}

Os chavões da "gestão da diversidade" e da "gestão estratégica", provindos das organizações empresariais e das suas "corporate culture", têm sido transferidos para as escolas, também elas agora idealizadas como "escolas de sucesso", "escolas eficazes", "escolas de qualidade", "escolas excelentes". Existem formas de orientação gerencialistas nos modelos atuais de gestão educacional. Esses modelos apresentam-se em consonância com os ditames da era da nova gestão e da racionalidade instrumental que a apoia. Integram-se nesses modelos gerencialistas generizados as propostas e a apologia do "poder no feminino" que podem conduzir a "novas formas de estereotipia gestionária". Pois, na era da nova gestão não se deixa de se proceder a uma inclusão estratégica de mais mulheres em cargos de gestão escolar de topo, o que está em consonância, aliás, com a ideologia da racionalização da emoção a favor da produtividade organizacional (ROCHA, 2005) e em correspondência com a defesa dos deveres das mulheres para o desenvolvimento económico sustentável (ROCHA, 2008a).

\section{CONCLUSÃO}

$\mathrm{Na}$ gestão das escolas, os discursos instituintes, mesmo que raros, configuram as possibilidades de fuga por parte dos homens e mulheres ao hierarquicamente instituído e configuram suas perceções sobre, por exemplo, o que é o poder, onde este se situa, quem o detém e como este pode suscitar transformações nos quotidianos de vida profissional, social e pessoal. Assim, fazer uma análise das relações de género enquanto relações de poder na gestão das escolas, a partir, simplesmente, das tradicionais ideologias diferenciadoras dos géneros, a partir dos condicionalismos das estruturas burocráticas das organizações educativas e do poder instituído, é não ter em consideração que tanto homens como mulheres convocam poderes instituintes e que estes e estas tanto operam na construção e reconstrução dos aspetos concretos e simbólicos dos contextos organizacionais como operam na sua desconstrução.

A diferenciação assimétrica entre os homens e as mulheres em contexto organizacional de gestão escolar é diluída em alguns dos discursos organizacionais, sobretudo naqueles em que se questionam os pressupostos da especificidade própria das práticas de gestão dos homens em relação às mulheres e vice-versa. Os limites da masculinidade organizacional, tal como os da feminilidade organizacional, a existirem, são difíceis de se traçarem num contexto em redefinição e em que os discursos dos homens e das mulheres revelam o quanto podem ser instáveis, ambíguas, múltiplas e complexas as relações de poder 
que entre si se desenvolvem. Não se despreze, para além disso, uma outra série de limites advindos da "gestão da diversidade" e da "gestão estratégica" e que instigam a uma nova gestão generizada.

Mesmo sabendo que as inovações relacionadas com a difusão de poderes e que as relações de gênero enquanto relações de poder se enfrentam com as mesmas dificuldades que as de qualquer outra inovação, esta análise crítica dos discursos organizacionais sobre discursos instituídos e discursos instituintes permite-nos, então, compreender as relações tensas que se estabelecem entre esses discursos e permite-nos reafirmar que, na escola como organização, os discursos instituintes, mesmo que raros, configuram as possibilidades de fuga, por parte dos homens e das mulheres - ou de outras (não)categorias de gênero ao hierarquicamente instituído e configuram suas perceções sobre, por exemplo, o que é o poder, onde este se situa, quem o detém e como este pode suscitar transformações nos cotidianos de vida.

Uma visão unitária do poder substantivo instituído não permite dar conta das relações de poder instituintes que, pesem embora os constrangimentos, podem-se desenvolver nas organizações educativas em que mulheres e homens trabalham. As relações de gênero, enquanto relações de poder, não são só relações de dominação, relações estáticas e para sempre inalteráveis, mas são, sim, relações complexas, dinâmicas, imprevisíveis e capacitantes.

Em suma, digamos que o poder deve ser concebido não como substantivo e unilateral, mas, antes, como relacional, ambíguo e complexo; as masculinidades e as feminilidades são essencialmente construções sociais, históricas e, por conseguinte, contingentes. São vetores analíticos que não têm existência independente uns dos outros. Se os conceitos de gênero, de poder e de gestão resultam de uma construção e reconstrução sociais, também podem estar sujeitos a desconstruções sociais e, nomeadamente, à desconstrução das oposições binárias e hierarquizantes: masculino/feminino; poder/não poder. Este confronto e questionamento é de sobremaneira importante num contexto em que a escola pública portuguesa foi sujeita a um processo de mudança ao nível do seu modelo de governação, com a publicação do Decreto-lei n. ${ }^{0}$ 75/2008 (PORTUGAL, 2008), de 22 de abril, que veio instituir a figura do Diretor de escola e que fez emergir a chamada gestão unipessoal. Por este e por muitos outros motivos, este trabalho está, neste momento, em processo de desenvolvimento.

\section{REFERÊNCIAS}

AFONSO, Natércio e VISEU, Sofia. A reconfiguração da estrutura e gestão das escolas públicas dos ensinos básicos e secundário - estudo extensivo. Programa 
de Avaliação Externa do Regime de Autonomia, Administração e Gestão das escolas e agrupamentos de escolas definido pelo Decreto-Lei 115-A/98 de 4 de Maio. Lisboa: Centro de Estudos da Escola, Faculdade de Psicologia e de Ciências da Educação da Universidade de Lisboa, 2001.

ALVESSON, Mats; BILLING, Ivonne D. Gender and Organization: Toward a Differentiated Understanding. Organization Studies. 13/12, p. 73-103,1992.

ARAÚJO, Helena Costa As Mulheres Professoras e o Ensino Estatal. Revista Crítica de Ciências Sociais. Coimbra, n. 29, p. 81-103, 1990.

BARNARD, Chester I. As Funções do Executivo. São Paulo: Editora Atlas, 1971.

BARROSO, João. Reitores, Revista do Fórum Português de Presidentes e Directores: Evolução e Paradoxos de uma Função. Administração Educacional. Revista do Fórum Português da Administração Educacional. Lisboa: Faculdade de Psicologia e de Ciências da Educação da Universidade de Lisboa. n. 2, p. 90107, 2002.

BOGDAN, Robert; BIKLEN, Sari. Investigação Qualitativa em Educação. Porto: Porto Editora, 1994.

CALÁS, Marta; SMIRCICH, Linda. Re-Writing. Gender into Organizational Theorizing: Directions from Feminist Perspectives. In: REED, M.; HUGHES, M. Rethinking Organization. London: Sage Publications, 1992, p. 227-253.

CORTESÃO, Luísa. Escola, Sociedade. Que Relação? Porto, Edições Afrontamento, 1988.

ENOMOTO, Ernestine K. Probing Educacional Management as Gendered: An Examination trough Model and Metaphor. Teacher College Record. v. 102, n. 2, p. 375-397, 2000.

ETZIONI, Amitai (Edit.). The Semi-Professions and their Organization. New York: Free Press, 1969.

FERGUSON, Kathy E. The feminist Case Against Bureaucracy. Philadelphia: Temple University Press, 1984.

FRASER, Nancy. Qué Tiene de Crítica la Teoria Crítica? Habermas y la Cuestion del Género. In : S. BENHABIB e D. CORNELL (Edits.). Teoria Feminista y Teoria Crítica. Valencia: Edicions Alfons el Magnànim, 1990, p. 49-88. 
FREIRE, João. Sociologia do Trabalho: Uma Introdução. Porto: Afrontamento, 1993.

GIDDENS, Anthony. Modernidade e Identidade Pessoal. Oeiras: Celta Editores, 1994.

GIDDENS, Anthony. Transformações da Intimidade. Oeiras: Celta Editores, 2001.

HALFORD, Susan; SAVAGE, Mike; WITZ, Anne. Gender, Careers and Organisations. Current Developments in Banking, Nursing and Local Government. London: Macmillan Press, 1997.

HEARN, Jeff et al. The Sexuality of Organization. London: Sage Publications, 1992.

MAGALHÃES, Maria José. Movimento Feminista e Educação. Oeiras: Celta Editora, 1998.

MARSHALL, Judi. Women Manager. Travellers in a Male World. New York: Wiley, 1984.

MARTIN, Joanne. The Organization of Exclusion: Institutionalization of Sex Inequality, Gendered Faculty Jobs and Gendered Knowledge in Organizational Theory and Research. Organization Articles. v. 1(2), p. 401-431. London: Sage Publications, 1994.

MILLS, Albert J. Organizational Discourse and the Gendering of Identity. In: HASSARD, J.; PARKER, M. (Edit.). Postmodernism and Organizations. 1993, p. 132-148.

MORGADE, Graciela. Dinamicas de Género en los Discursos Constitutivos de la Gestión de las Escuelas Primarias Argentinas. Educação e Realidade. n. 23(1), p. 73-85, 1998.

O’ LEARY, Virgínia E.; RYAN, M. M. Women bosses: Counting the changes or changes that count. In: M. TANTON (Edit.). Women in Management. A Developing Presence. London; New York: Routledge, 1994, p. 63-78.

PORTUGAL. Decreto-lei n. ${ }^{\mathbf{7}} \mathbf{7 5}$, de 22 de abril de 2008. Lisboa: Ministério da Educação.

ROCHA, M. Custódia J. As Relações de Género e os Estudos sobre as Organizações Educativas - Problematização. In: A. LUÍS, J. BARROSO e J. PINHAL (Edit.). 
Actas do $1^{\circ}$ Congresso do Forum Português de Administração Educacional - A Administração da Educação: Investigação, Formação e Práticas. Lisboa: Forum Português de Administração Educacional, 1997, pp. 249-264.

ROCHA, M. Custódia J. Democracia e Participação. A Feminização da Gestão Escolar e a Realização da Escola Democrática. Revista de Educação. v. VII, n. 2, p. 29-40, 1998.

ROCHA, M. Custódia J. Relações Sociais de Género e Gestão Educacional: A Nova Dinâmica da Racionalidade Instrumental. Gestão em Ação. n. 8, v. 2, p. 131-145, 2005.

ROCHA, M. Custódia J. Educação, Género e Poder: Uma Análise Política, Sociológica e Organizacional. Braga: Universidade do Minho, Centro de Investigação em Educação, 2007a.

ROCHA, M. Custódia J. Género e Poder na Gestão Educacional: Os contributos de uma análise crítica dos discursos organizacionais. Configurações - Revista de Sociologia, n. 3, p. 69-72, 2007b.

ROCHA, M. Custódia J. Dos Direitos das Mulheres como Direitos Humanos Indivisíveis aos Deveres das Mulheres para o Desenvolvimento Económico Sustentável. Org \&Demo, n. 9, p. 143-161, 2008a.

ROCHA, M. Custódia J. Para uma Desconstrução de Alguns Pressupostos Existentes sobre Género, Discurso e Poder. Actas do VI Congresso Português de Sociologia. Mundos Sociais: Saberes e Práticas, p. 1-11. Lisboa: Associação Portuguesa de Sociologia, 2008b.

SANCHES, Mária de Fátima C. Reformar o Contexto da Gestão das Escolas Secundárias: A Voz dos Conselhos Directivos. Revista de Educação. v.. I, n.. 2, p. 27-39, 1987.

SHAKESHAFT, Charol. Women in Educational Administration. London: Sage Publications, 1989.

SHAKESHAFT, Charol The Stuggle to Create a More Gender-Inclusive Profession. In: J. MURPHY, J.; LOUIS, K. S. (Edits.). Handbook of Research on Educational Administration. San Francisco: Jossey-Bass Publishers, 1999, p. 99-118.

SILVA, Manuela. A igualdade de Género. Caminhos e Atalhos para uma Sociedade Inclusiva. Lisboa: Comissão para a Igualdade e para os Direitos das 
Mulheres, 1999.

SIMPSON, Richard; SIMPSON, Ida. Women and Bureaucracy in the SemiProfessions. A. ETZIONI (Edit.). In: The Semi-Professions and their Organization. New York: Free Press, 1969, p. 196-265.

TRIGO-SANTOS, Florbela (1997). As Mulheres e a Liderança Educacional. LUÍS, A; BARROSO, J.; PINHAL, J. (Edits.). Actas do $\mathbf{1}^{\circ}$ Congresso do Forum Português de Administração Educacional - A Administração da Educação: Investigação, Formação e Práticas. Lisboa: Forum Português de Administração Educacional, 1997, p. 239-246.

VARGHESE, Mariamma A. Women Administrators in Education. New Delhi: Vikas Publishing House, 1990.

WEBER, Max. Ensaios de Sociologia. Rio de Janeiro: Zahar Editores, 1979.

YIN, Robert. Estudo de caso: Procedimentos e Métodos. Porto Alegre: Bookman 2a ed., 2001.

YOUNG, Iris. Imparcialidade y lo Cívico Público. In: BENHABIB, S.; CORNELL, D. (Edits.). Teoria Feminista y Teoria Crítica. Valencia: Edicions Alfons el Magnànim, 1990, p; 89-117.

MARIA CUSTÓDIA JORGE ROCHA possui PhD. Investigadora do Centro de Investigação em Educação (CIEd), professora auxiliar do Departamento de Ciências Sociais da Educação -Instituto de Educação- Universidade do Minho, Campus de Gualtar, Braga, Portugal. E-mail: mcrocha@ie.uminho.pt

TÂNIA SUELY ANTONELLI MARCELINO BRABO possui graduação em Pedagogia pela Universidade Estadual Paulista Júlio de Mesquita Filho (1991), mestrado em Educação pela Universidade Estadual Paulista Júlio de Mesquita Filho (1997), doutorado em Sociologia pela Universidade de São Paulo (2003) e pós-doutorado em Educação pela Universidade do Minho-Braga-Portugal (2007). Investigadora visitante no Instituto de Ciências Sociais da Universidade de Lisboa (2007). PósDoutorado (2012) na Universidade de Valência-Espanha. Atualmente é professora assistente doutora efetiva da Universidade Estadual Paulista Júlio de Mesquita Filho. Tem experiência na área de Educação, com ênfase em Administração de Unidades Educativas e Políticas Educacionais, atuando principalmente nos seguintes temas: gestão democrática, direitos humanos, gênero, cidadania e educação.

Recebido em janeiro de 2015 Aprovado em setembro de 2015 